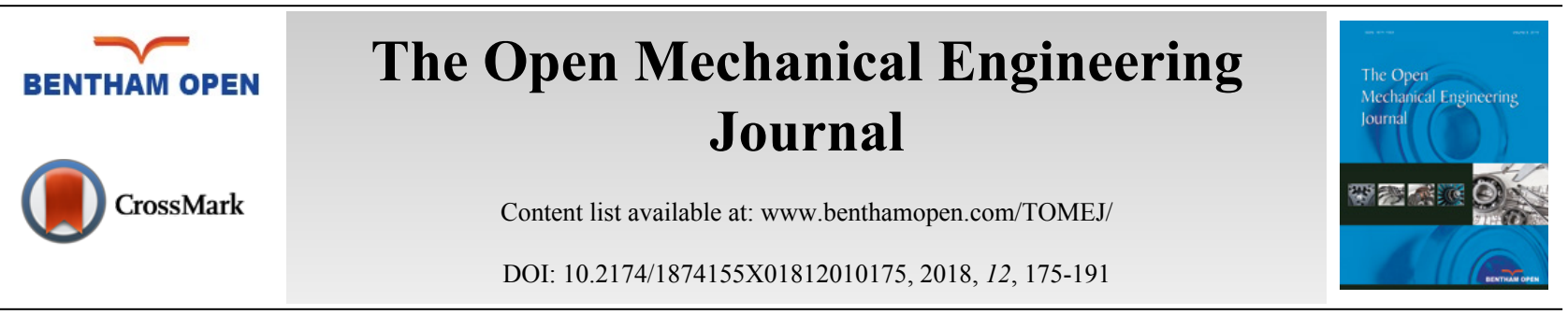

RESEARCH ARTICLE

\title{
Experimental Studying of the Variations of Surface Roughness and Dimensional Accuracy in Dry Hard Turning Operation
}

\author{
S. Yousefi ${ }^{*}$ and M. Zohoor \\ Faculty of Mechanical Engineering, K. N. Toosi University of Technology, Tehran, Iran
}

Received: June 9, 2018

Revised: September 24, 2018

Accepted: September 25, 2018

\section{Abstract: \\ objective:}

Hard turning in dry condition using cubic boron nitride tools, as an alternative of traditional grinding operation, is an advanced machining operation in which hardened steel with the hardness greater than $46 \mathrm{HRc}$ is machined without the use of any coolant.

\section{Method:}

In the hard turning process, due to its hard nature, usually the cutting depth is selected lower than or equal to the nose radius, and the cutting zone is mainly limited within the tool nose area. Thus, unlike the traditional turning, the effect of the nose radius on the surface finish and dimensional accuracy becomes more complicated. Therefore, in this paper, firstly, the effect of processing parameters such as nose radius on the surface roughness and dimensional accuracy is investigated. Then, the relationship between the surface finish and dimensional accuracy variations with vibration, cutting forces, and tool wear is studied experimentally. The results revealed that feed rate is the most important factor influencing the surface roughness, whereas spindle speed and cutting depth are insignificant factors. On the other hand, cutting depth and spindle speed have the greatest effect on the dimensional accuracy, while nose radius has no significant effect. The vibration and wear analysis revealed that compared with the vibration, the tool wear has no considerable effect on the dimensional accuracy. It was also observed that the spindle speed has a contradictory effect on the surface roughness and dimensional accuracy. The best dimensional accuracy is obtained at $500 \mathrm{rpm}$, while the best surface quality is achieved at $2000 \mathrm{rpm}$.

\section{Result:}

The obtained results also showed that increasing the feed rate from a particular value not only leads to no significant changes in the surface roughness value but in some cases can also decrease the surface roughness.

\section{Conclusion:}

According to the analysis results, the lowest cutting depth, the moderate feed rate, and the speed lower than $1100 \mathrm{rpm}$ provide the best dimensional accuracy. Compared with carbides and ceramics, cubic boron nitride tools produce a better surface roughness at both higher cutting depth and speed. $0.202 \mu \mathrm{m}$ is the best surface roughness that was obtained at $\mathrm{r}_{\varepsilon}=1.2 \mathrm{~mm}, \mathrm{~N}=2000 \mathrm{rpm}, \mathrm{f}=0.08$ $\mathrm{mm} / \mathrm{rev}, \mathrm{d}=0.5 \mathrm{~mm}$ which is comparable with the surface quality obtained by the conventional grinding operation.

Keywords: Vibration, Dry hard turning, Tool wear, Surface roughness, Dimensional accuracy, Cubic boron nitride, Cutting force.

\section{INTRODUCTION}

Hard turning in dry condition using cubic boron nitride (CBN) tool, as an alternative of traditional turning-grinding processes, is an advanced machining process in which hardened steels with the hardness greater than $46 \mathrm{HRC}$ are machined without the use of any cutting fluid [1-10]. Hard turning reduces the additional processing steps, like heat

\footnotetext{
* Address correspondence to this author at the Faculty of Mechanical Engineering, K. N. Toosi University of Technology, Tehran, Iran;
} Tel: 00989111133970; E-mail: sasan_6262@yahoo.com 
treatment and grinding, which are used during the traditional machining of hard materials [11-20].

Cubic boron nitride $(\mathrm{CBN})$ tools are the best option for cutting hard materials. $\mathrm{CBN}$ due to high thermal shock resistance and hardness at high temperature is ideal for machining hard materials. Advanced CBN inserts are composed of ceramic binder with $45-70 \% \mathrm{CBN}$. These grades of the $\mathrm{CBN}$ inserts have high wear resistance due to their ceramic binder. Another group of the $\mathrm{CBN}$ inserts is composed of $85-100 \% \mathrm{CBN}$ and a metallic binder that increases the insert toughness. CBN is usually brazed onto a cemented carbide carrier to form a cutting insert. It should be noted that the high content ferrite in soft steels with the hardness below 45 HRC decreases the wear resistance of the CBN tools. Therefore, as an alternative for traditional grinding, the CBN cutting tools are suitable for the machining of hardened steels with hardness over 45 HRC. As a result, a substantial reduction in production costs and appropriate surface quality and accuracy can be achieved simultaneously.

At the hard turning, for a given workpiece material and cutting tool, selecting appropriate processing parameters is so crucial for achieving appropriate performance and production cost. The performance of the hard turning is evaluated by the criteria like surface roughness, dimensional accuracy, cutting forces, tool wear, and power consumed [2, 21-30]. Nowadays, in metal cutting industries, main concern is to find the final quality of the machined component such as surface finish and dimensional accuracy [6, 21-49]. The surface roughness $\left(R_{a}\right)$ is an effective factor affecting the surface coating, wear resistance, lubrication ability, fatigue life, friction coefficient, and corrosion resistance of the machined component $[4,5]$. The dimensional accuracy is another important quality criterion, which is defined as the difference between the desired depth of cut and obtained cutting depth. The dimensional accuracy significantly affects the machining cost and time. By selecting appropriate processing parameters, the dimensional accuracy improves, and therefore, the additional cutting pass is reduced. As a result, the machining cost and time will be reduced significantly $[1,3,4,5,11-17]$.

AISI 4140 is a low-alloy and medium-carbon steel with $65 \%$ machinability, containing chromium and molybdenum as strengthening agents. Some important applications in the automotive, aerospace, and oil - gas industries include parts such as pump shafts, tool holders, engine construction, jigs and fixtures, crankshafts, connection rods, chuck bodies, and forged gears [8-14].

Up to now, the dimensional accuracy variation in the dry hard turning with the CBN tools has not been studied experimentally. In addition, the relationship between the surface finish and dimensional accuracy variations with vibration, cutting forces, and tool wear in the hard turning using CBN has not been investigated comprehensively.

For example, Akkus et al. [5] only compared neural network and fuzzy logic based modeling with regression methods to model the surface finish of AISI4140 (51 HRC). In their predictive models feed rate, cutting depth, and cutting speed were the main variables. The results showed that the fuzzy logic based model predicts the surface roughness better than ANN, and also the ANN predicts the surface roughness better than the regression methods.

Asilturk et al. [12] by using coated carbide inserts, determined the influence of depth of cut (d), feed speed (f) and cutting speed $(V)$ on the quality of the machined surface $\left(R_{a}, R_{z}\right)$ of AISI 4140 with 51 HRC hardness. Their statistical analysis showed that compared with the other selected factors, the feed rate significantly affects the $R_{a}$ and $R_{z}$ values. In other research work, Yallese et al. [14] by using different ceramic inserts analyzed the surface roughness alteration for AISI 4140 with $60 \mathrm{HRC}$ hardness. They found that for both conventional and wiper inserts, the quality of the machined surface is significantly affected by varying feed rate and cutting depth. They proposed the lowest feed rate and cutting depth and the highest spindle speed as the ideal combination to achieve a minimum surface roughness. They also claimed that by using wiper ceramic inserts the surface finish will be improved significantly. In a similar research work, Chavoshi et al. [18] using CBN inserts investigated the variations of the surface roughness under various spindle speed and material hardness. They found that the surface roughness variations strongly depend on the hardness of the component, while spindle speed has no significant effect. In addition, their experiments revealed that in the range of 35 to $55 \mathrm{HRC}$, increasing the component hardness leads to increase in the surface quality, but further increase in the hardness deteriorates the surface quality. Therefore, at different spindle speeds, the best surface roughness was achieved at $55 \mathrm{HRC}$. Their results also showed that the artificial neural network predicts the $\mathrm{R}_{\mathrm{a}}$ better than the regression method. Some other researchers studied experimentally the variations of surface finish and tool wear during the hard turning of AISI4140 [19, 20, 21]. In addition, mathematical predictive models were developed for the flank wear and surface finish. Compared with the surface finish, the researches about the dimensional accuracy in the dry hard turning have been even more limited. For example, Dhar et al. [44-45] studied the effect of minimum quantity lubrication (MQL) on the dimensional deviation and surface roughness of AISI4340 and AISI1040 steel in the conventional turning operation. 
Finally, they concluded that in the conventional turning, the surface roughness and dimensional accuracy are improved with MQL. Risbood et al. [46] claimed that the dimensional accuracy and surface roughness are predicted accurately by measuring the cutting forces and vibrations. They also proved that a neural network is an effective tool for the prediction of the dimensional deviation and surface roughness of carbon steel with 130 BHN hardness. Some other researchers studied the tool wear, dimensional accuracy, and surface roughness of alloy steels under cryogenic condition such as Dhar et al. [47-48]. They concluded that the cryogenic cooling by liquid nitrogen jets significantly decreases the tool wear, dimensional deviation, and surface roughness, compared to the dry and wet conventional turning. In a novel research attempt, Shahabi et al. [49] used a machine vision approach to predict the surface roughness and dimensional accuracy in the conventional turning of AISI 304 stainless steel. They used 2D images of cutting tools to develop mathematical models for predicting the surface roughness and dimensional deviation.

As discussed earlier, the dimensional accuracy variation in the dry hard turning especially with the CBN tools has not been studied until now. In addition, the effect of vibration, cutting forces, and tool wear on the surface finish and dimensional accuracy variations in the hard turning have not been discussed comprehensively. In the hard turning process, due to the high workpiece material hardness, small cutting depth is selected, and therefore, almost always the cutting depth becomes lower than or equal to the nose radius, and the cutting zone is mainly limited within the tool nose area. Thus, unlike the traditional turning, the effect of the nose radius on the surface finish and dimensional accuracy becomes more complicated. Thus, in this paper, first the influence of processing parameters such as tool nose radius ( $r_{\varepsilon}$ ), cutting depth $(d)$, spindle speed $(N)$, and feed rate $(f)$ on the dimensional accuracy $(\Delta d)$ and surface roughness $\left(R_{a}\right)$ of hardened steel using CBN cutting tool is investigated. Then, the effect of vibration, cutting forces, and tool wear is studied on the surface finish and dimensional accuracy. Finally, the optimal combinations, which results in the best dimensional accuracy and surface roughness are determined experimentally.

\section{MATERIAL AND METHODS}

The experiments were conducted on FANUC series Oi Mate-TC industrial CNC lathe (CAK61407/100). For increasing the rigidity of the machining during the experiments, the workpieces were fixed between three-jaw chuck and tailstock. Standard CBN inserts (ISO code CNGA120404S010-30A, CNGA120408S010-30A, CNGA120412S010 $-30 \mathrm{~A}$ ) made by Sandvik ${ }^{\mathrm{TM}}$ Coromant were used as the cutting tools with the following geometry: Clearance angle $=0^{\circ}$, chamfer angle $=30^{\circ}$, chamfer width $=0.10 \mathrm{~mm}$, edge thickness $=4.76 \mathrm{~mm}$, edge length $=12 \mathrm{~mm}$, and rhombic tip angle $=80^{\circ}$. The same inserts with different nose radius of $0.4 \mathrm{~mm}, 0.8 \mathrm{~mm}$, and $1.2 \mathrm{~mm}$ were used for analysis the nose radius effect. The chosen inserts (CB7025 grades) were composed of ceramic binder with $60 \% \mathrm{CBN}$. The tool holder used in the experiments was standard DCBNR $/ \mathrm{L}-2525 \mathrm{M}$ with entering angle $=75^{\circ}$, rake angle $=-6^{\circ}$, inclination angle $=-6^{\circ}$, and clearance angle $=6^{\circ}$. The inserts were clamped on the holder with the tightening torque of $3.9 \mathrm{Nm}$ according to the cutting tool manufacturer's recommendation. In order to have a stable cutting condition, each experiment was performed with a new sharp insert. Round bars of 55 HRC AISI4140 (MO40) steel with $31 \mathrm{~mm}$ diameter and 80 mm length were used for the experiments. The workpiece composition is presented in Table 1. A pre-cut with $0.25 \mathrm{~mm}$ cutting depth was performed before hardening the steel to remove the rusts and oxide layers from the surface of the workpiece. The initial diameter of the workpiece was kept constant for each test, thus, the cutting speeds according to the spindle speeds of 500, 1000 and $2000 \mathrm{rpm}$ were 50, 100 and $200 \mathrm{~m} / \mathrm{min}$ respectively, which remained constant during the experiments. Due to the importance of the dry machining in the modern industry, the tests were performed under the dry condition without any fluid, gas and/or solid coolant. After each individual test, the surface roughness measurements were carried out immediately by using Mitutoyo (SJ-201P) roughness tester with 0.8 mm cut-off value and sampling length of $4.8 \mathrm{~mm}$, in accordance to ISO/DIS 4287/1E. The surface roughness values were measured at five equally spaced locations along the cutting length. The average of this five roughness values was taken as the arithmetic surface roughness value $\left(\mathrm{R}_{\mathrm{a}}\right)$. This measuring process was repeated three times for each test and their average was considered as the final surface roughness. The maximum flank wear $\left(\mathrm{VB}_{\max }\right)$ was measured and recorded after each test using an OLYMPUS optical microscope. A piezoelectric type vibration meter (type SI-327A01) was also used to measure the acceleration of the radial vibration of the insert holder. Three component of turning forces (i.e. feed force, cutting force, and radial force) were measured precisely by using a Kistler piezoelectric turning dynamometer (type 9257BA) and a signal amplifier (type 5233A) connected to a control unit, data acquisition board and microcomputer. The dimensional accuracy was also determined by measuring the dimensional deviation. As explained earlier, the dimensional deviation is defined as the difference between the desired cutting depth and the obtained depth of cut. The diameter deviation was measured using a precision dial gauge with an accuracy of $\pm 0.01 \mathrm{~mm}$. Diameter deviation was measured at five equally spaced points along the cutting length and the average of these five values considered as the 
dimensional deviation. It is important to note that all of the measurements were repeated three times for each test. In the current study, cutting depth, nose radius, feed speed, and cutting speed were considered as the processing variables. The variables were chosen according to the recommendation of the cutting tool catalogues. In order to conduct a comprehensive study, the cutting depth and feed speed with a wider range were selected compared with the ranges chosen by the previous researchers in the hard turning operation. The relative errors for all the experiments were less than $15 \%$.

Table 1. Chemical composition of the workpiece.

\begin{tabular}{|c|c|c|c|c|c|c|c|c|c|c|c|c|}
\hline $\mathbf{C} \%$ & $\mathbf{S i} \%$ & $\mathbf{M n} \%$ & $\mathbf{P \%}$ & $\mathbf{S \%}$ & $\mathbf{C r \%}$ & $\mathbf{M o \%}$ & $\mathbf{N i} \%$ & $\mathbf{C u \%}$ & $\mathbf{A l \%}$ & $\mathbf{T i} \%$ & $\mathbf{S n \%}$ & $\mathbf{V \%}$ \\
\hline 0.43 & 0.24 & 0.79 & $<0.035$ & 0.024 & 1.10 & 0.19 & 0.022 & 0.025 & 0.029 & 0.004 & 0.002 & 0.005 \\
\hline
\end{tabular}

\section{RESULT AND DISCUSSIONS}

The results showed that by varying the feed speed, the surface roughness is altered significantly. The next important factor influencing the surface roughness is the nose radius. In addition, compared to the feed rate and nose radius, the effect of cutting depth and spindle speed on the surface roughness is negligible. On the other hand, the cutting depth significantly affects the dimensional deviation, while the nose radius has no considerable effect on the dimensional deviation. The spindle speed is also the next important factor affecting the diameter deviation.

\subsection{The Effect of Spindle Speed (N)}

Fig. (1) shows the variations of the surface roughness at different cutting conditions. As explained earlier, because the initial diameter of the workpiece was kept constant during the experiments, the cutting speed according to the spindle speed of 500, 1000 and $2000 \mathrm{rpm}$ were 50,100 and $200 \mathrm{~m} / \mathrm{min}$ respectively, which remained constant during the experiments. This means that, for example, 500-rpm spindle speed is equal to $50 \mathrm{~m} / \mathrm{min}$ cutting speed for all experiments. According to Fig. (1), increasing the spindle speed leads to the linearly improvement of the surface finish. This behavior can be attributed to the decreasing the cutting force at high cutting speed due to the higher cutting temperature. Fig. (2) completely confirm this subject. It is obvious from Fig. (2) that by increasing the cutting speed, the forces are decreased significantly, due to the thermal softening of the workpiece material. Hence, the highest level of the spindle speed produces the best surface roughness. Chavoshi et al. [18] reported a similar result for the CBN cutting tool. They observed that for AISI4140 steel with 50-55 HRC hardness, the surface roughness gradually decreases with increasing the spindle speed up to $3000 \mathrm{rpm}$. However, different results have reported for ceramic and coated carbide inserts $[12,20]$. For the ceramic and coated carbide inserts, the variation of the $\mathrm{R}_{\mathrm{a}}$ with the cutting speed is generally divided into two zones. In the first zone, by increasing the cutting speed the surface roughness decreases until the lowest value is obtained, then by a further increase in the cutting speed the surface roughness increases with a high slope (second zone). Researchers attributed this behavior to the restriction of the BUE formation in the first zone (improved surface roughness) and the increase in machine vibration in the second zone (worsened surface roughness). It was also seen that the average of the $R_{a}$ values decreases from $4.08 \mu \mathrm{m}$ to $2.245 \mu \mathrm{m}$ when the spindle speed is gradually increased from $500 \mathrm{rpm}$ to $2000 \mathrm{rpm}$. Thus, the surface roughness is improved about 55\% when the spindle speed increases $400 \%$.

Fig. (3) shows the influence of the spindle speed on the variations of the dimensional deviation. It is obvious that when the spindle speed is increased gradually, the dimensional accuracy decreases. This degradation is due to the increase in the tool vibration at higher speeds. The variations of tool vibration, which were obtained under various machining conditions completely prove this claim. As shown in Fig. (4), by increasing the spindle speed, the vibration increases. As a result, this higher produced vibration deteriorates the dimensional accuracy. In addition, at higher cutting speeds, especially in the dry machining, due to the higher cutting temperature, thermal expansion of the workpiece becomes more serious. Therefore, the thermal expansion can be another negative factor affecting the dimensional accuracy in the dry hard turning operation. According to the results, the best dimensional accuracy is obtained at $500 \mathrm{rpm}$, while the best surface quality was achieved at $2000 \mathrm{rpm}$. Therefore, it can be concluded that the spindle speed has a contradictory effect on the surface quality and dimensional accuracy. This effect has to be considered in the cases where a high dimensional accuracy is required along with great surface finish. 


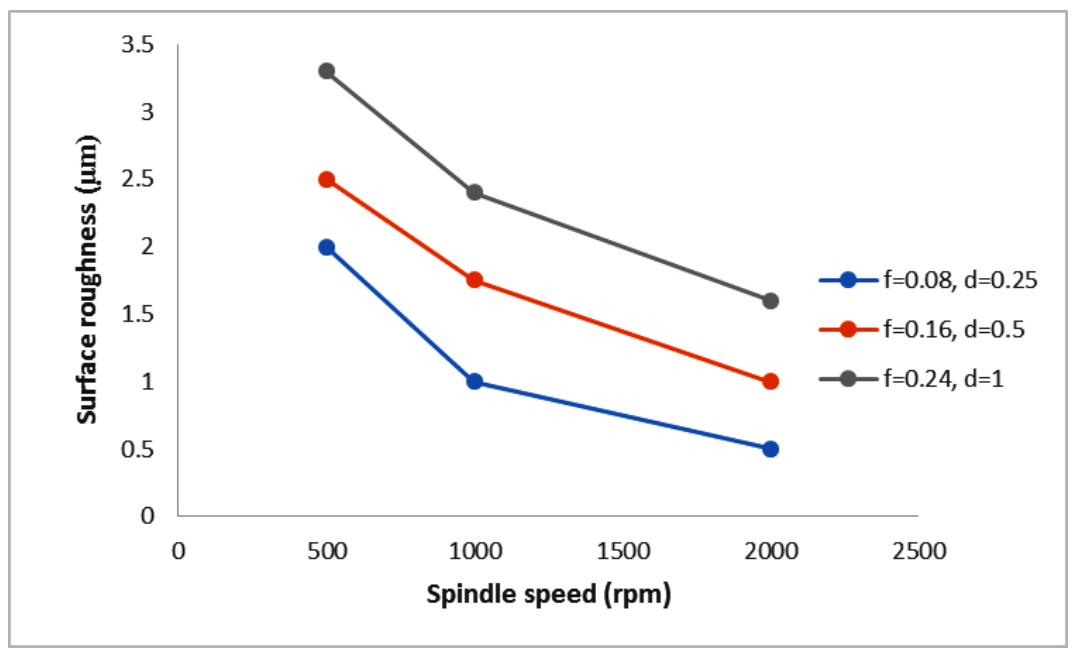

Fig. (1). The effect of the spindle speed on the surface roughness variations under different machining conditions $\left(\mathrm{r}_{\varepsilon}=0.8 \mathrm{~mm}\right)$.

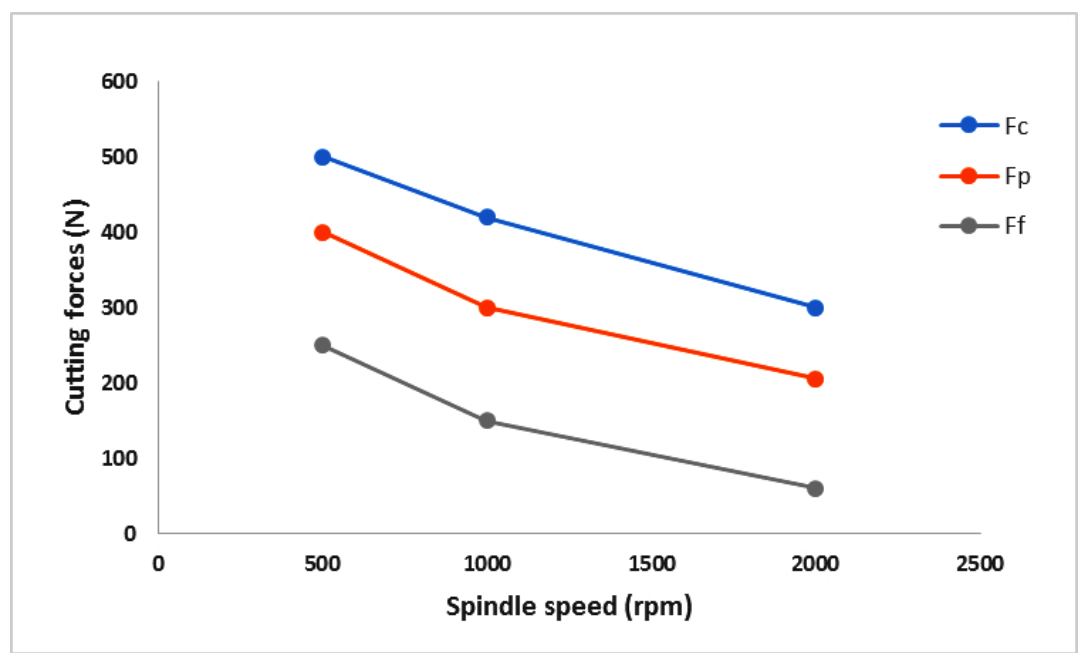

Fig. (2). The effect of the spindle speed on the cutting forces $\left(\mathrm{f}=0.16 \mathrm{~mm} / \mathrm{rev}, \mathrm{d}=0.5 \mathrm{~mm}, \mathrm{r}_{\varepsilon}=0.8 \mathrm{~mm}\right)$.

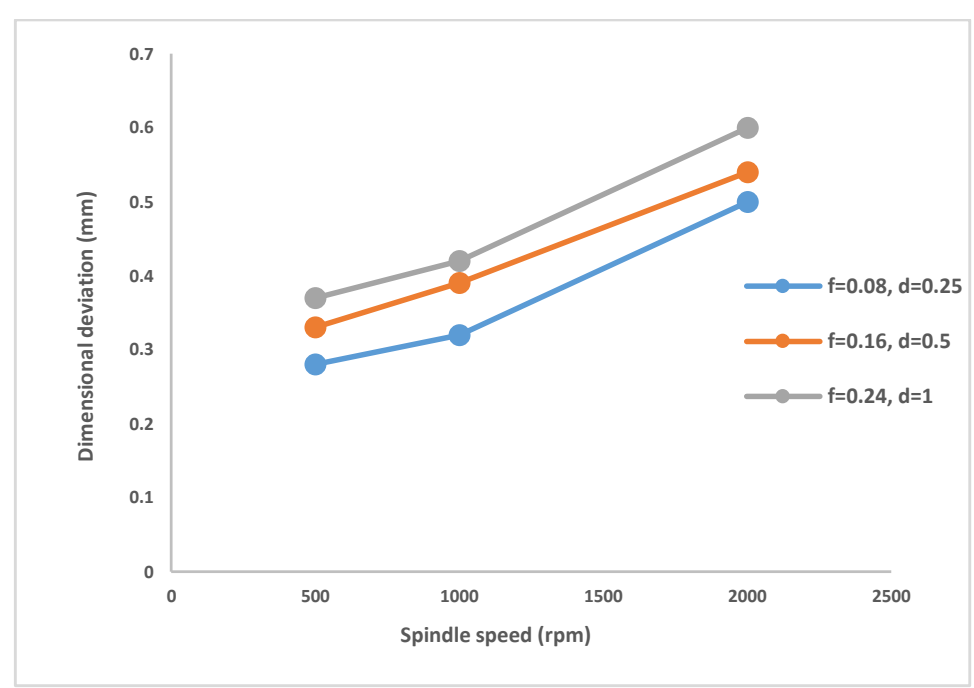

Fig. (3). The effect of the spindle speed on the dimensional deviation under different machining parameters $\left(\mathrm{r}_{\varepsilon}=0.8 \mathrm{~mm}\right)$. 


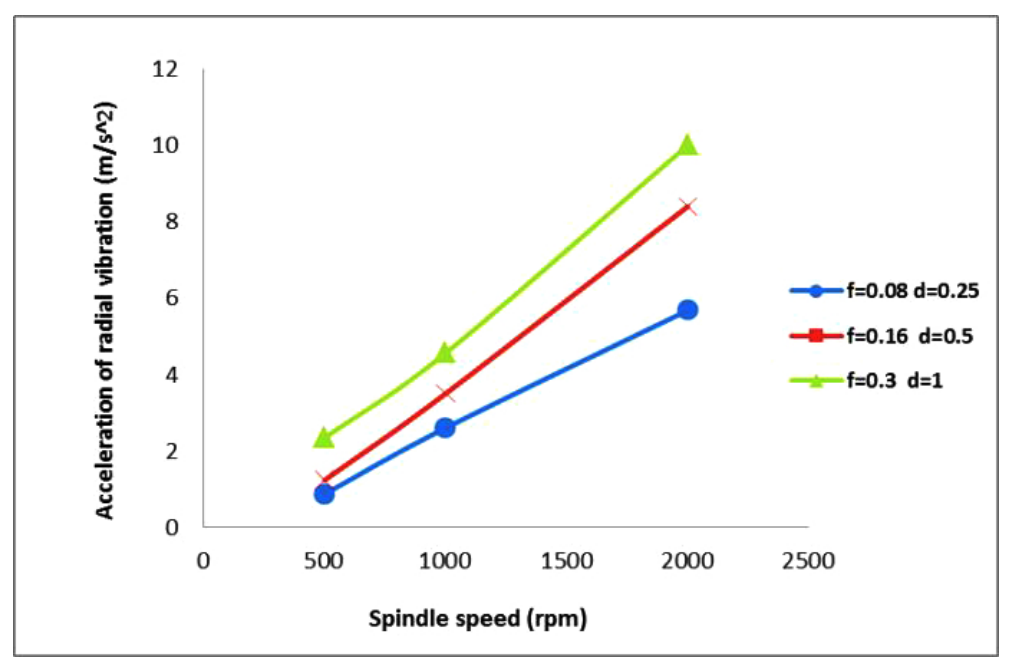

Fig. (4). The effect of spindle speed on the machining vibration under various machining parameters $\left(\mathrm{r}_{\varepsilon}=0.8 \mathrm{~mm}\right)$.

\subsection{The Effect of Insert Nose Radius $\left(r_{\varepsilon}\right)$}

As discussed earlier, nose radius is the second important factor that affects the surface roughness. Small nose radius reduces the vibration, but because of low strength, it is ideal for small cutting depths. On the other hand, large nose radius is used at larger cutting depths and higher feed rates, due to its stronger cutting edge. The great challenges of using large nose radius are high radial forces and vibration [7]. As explained earlier, in the hard turning process, due to its hard nature, cutting zone is mainly limited within the tool nose area because almost always the cutting depth is selected lower than or equal to the nose radius. As a result, the insert nose is exposed to severe pressure and temperature, which result in serious wear or even occurring fracture. Thus, unlike the traditional turning operation, the effect of the nose radius on the surface finish and dimensional accuracy becomes more complicated.

As shown in Fig. (5), increasing the nose radius leads to the surface roughness improvement. Similar results were obtained for ceramic and cemented carbide tools during the AISI 52100 and 1030 hard turning respectively [4, 13, 39]. In all cases, the worst surface finish was obtained at $0.4 \mathrm{~mm}$ nose radius. This is related to the low strength of the tool tip and as a result, the higher rate of wear in that zone. Fig. (6) obviously confirmed this matter because the greatest tool wear seen at $r_{\varepsilon}=0.4 \mathrm{~mm}$. Furthermore, the relatively short contact length between the tool tip and the workpiece results in the lower heat dissipation from the shear zone and higher heat and stress concentration in that area. Thus, the possibility of the tool wear or even the thermoplastic deformation of the nose area is increased. When the nose radius is increased from $0.4 \mathrm{~mm}$ to $1.2 \mathrm{~mm}$, the surface roughness improves about $51 \%$. As shown in Fig. (6), this is related to the reduction of the flank wear at the larger nose radius. The results prove that the surface roughness is sensitive to the simultaneous variation of the cutting depth and nose radius. It was also observed that at $f=0.08$, the surface roughness becomes less sensitive to the changes in the nose radius. In all cases, the $1.2 \mathrm{~mm}$ nose radius yields a more acceptable range of surface roughness under various cutting conditions compared with the $0.8 \mathrm{~mm}$ nose radius. The wear analysis proves this behavior because the lowest amount of the flank wear was seen at $1.2 \mathrm{~mm}$ nose radius and, as a result, a better surface roughness is achieved with $1.2 \mathrm{~mm}$ nose radius. Furthermore, it was observed that the best surface roughness of $0.202 \mu \mathrm{m}$ was obtained using $1.2 \mathrm{~mm}$ nose radius. Table 2 shows the best-reported surface finish for machining hardened AISI4140 steel. As indicated in Table 2, for the carbide and ceramic tools, the best $\mathrm{R}_{\mathrm{a}}$ values were achieved when $0.8 \mathrm{~mm}$ nose radius was used, while for CBN tools the best $\mathrm{R}_{\mathrm{a}}$ was obtained using $1.2 \mathrm{~mm}$ nose radius. In general, it can be said that at CBNs like the ceramics and carbides, the surface roughness is improved with increasing the nose radius, but unlike the ceramics and carbides, the best surface roughness is obtained with $r_{\varepsilon}=1.2 \mathrm{~mm}$. However, some researchers claimed that further increasing of the nose radius from $1.2 \mathrm{~mm}$ deteriorates the surface roughness due to the greater plowing that occurs in the plastic deformation $[26,28,38,39]$. This high plowing may be related to the reduction of maximum uncut chip thickness due to increase in the insert nose radius. In the range of $0.4-1.2 \mathrm{~mm}$, larger nose radius provides better surface quality and shallower white layer, but wear, vibration, and cutting energy increase subsequently. 
Table 2. The best-reported surface roughness $\left(R_{\mathrm{a}}\right)$ and related cutting parameters for the hard turning of AISI 4140 steel.

\begin{tabular}{|c|c|c|c|c|c|c|c|}
\hline Reference & Type of Insert & $\begin{array}{c}\text { Feed Rate } \\
(\mathrm{mm} / \mathrm{rev})\end{array}$ & $\begin{array}{l}\text { Depth of Cut } \\
\text { (mm) }\end{array}$ & $\begin{array}{c}\text { Cutting Speed } \\
(\mathrm{m} / \mathrm{min})\end{array}$ & $\begin{array}{l}\text { Nose Radius } \\
(\mathbf{m m})\end{array}$ & $\begin{array}{c}\text { Hardness } \\
\text { (HRC) }\end{array}$ & $\begin{array}{c}\text { Best } R_{\mathrm{a}} \\
(\mu \mathrm{m})\end{array}$ \\
\hline Current study & $\mathrm{CBN}$ & 0.08 & 0.5 & 200 & 1.2 & 60 & 0.202 \\
\hline [Akkuş et al.] & Coated carbide & 0.18 & 0.2 & 120 & 0.8 & 62 & 0.940 \\
\hline [Asiltürk et al.] & Coated carbide & 0.18 & 0.6 & 150 & 0.8 & 57 & 1.170 \\
\hline [Elbah et al.] & Wiper ceramic & 0.08 & 0.2 & 115 & 0.8 & 60 & 0.240 \\
\hline [Elbah et al.] & Ceramic & 0.08 & 0.2 & 150 & 0.8 & 60 & 0.640 \\
\hline [Chavoshi et al.] & $\mathrm{CBN}$ & 0.1 & 0.3 & 190 & 1.2 & 60 & 0.222 \\
\hline [Das et al.] & $\mathrm{Al}_{2} \mathrm{O}_{3}+\mathrm{TiCN}$ mixed ceramic & 0.05 & 0.2 & 180 & 0.8 & 52 & 0.714 \\
\hline [Aslan et al.] & $\mathrm{Al}_{2} \mathrm{O}_{3}+\mathrm{TiCN}$ mixed ceramic & 0.05 & 0.25 & 100 & 0.8 & 63 & 0.688 \\
\hline
\end{tabular}
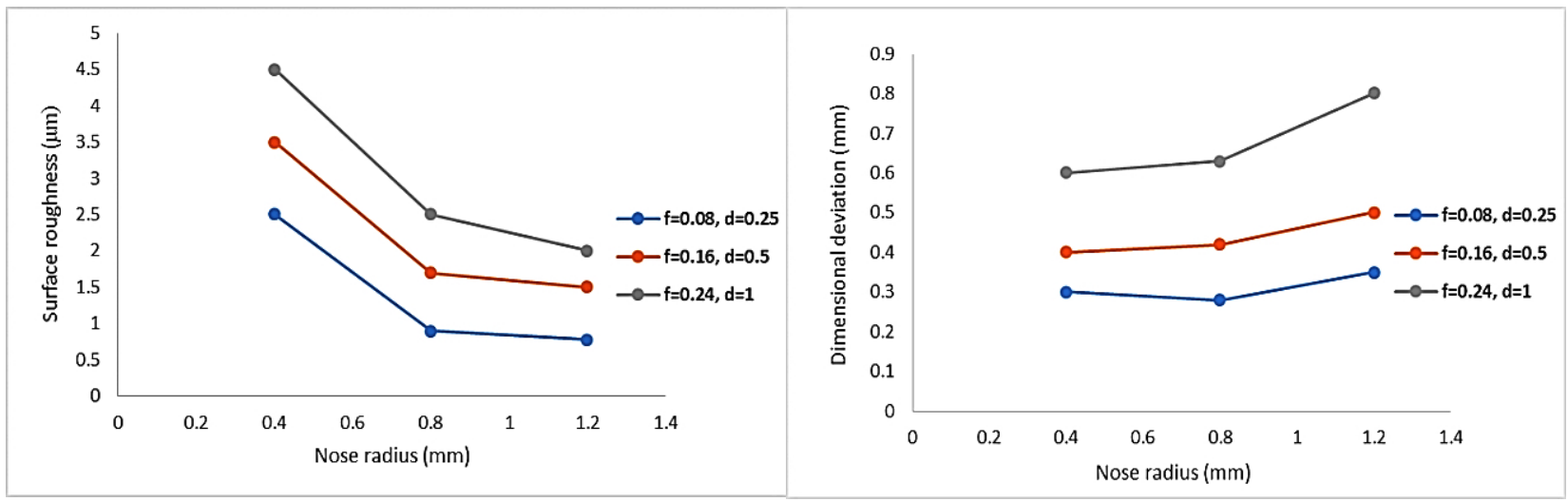

Fig. (5). The effect of the insert nose radius on the surface finish \& dimensional deviation under various machining parameters $(\mathrm{N}=1000 \mathrm{~mm})$.

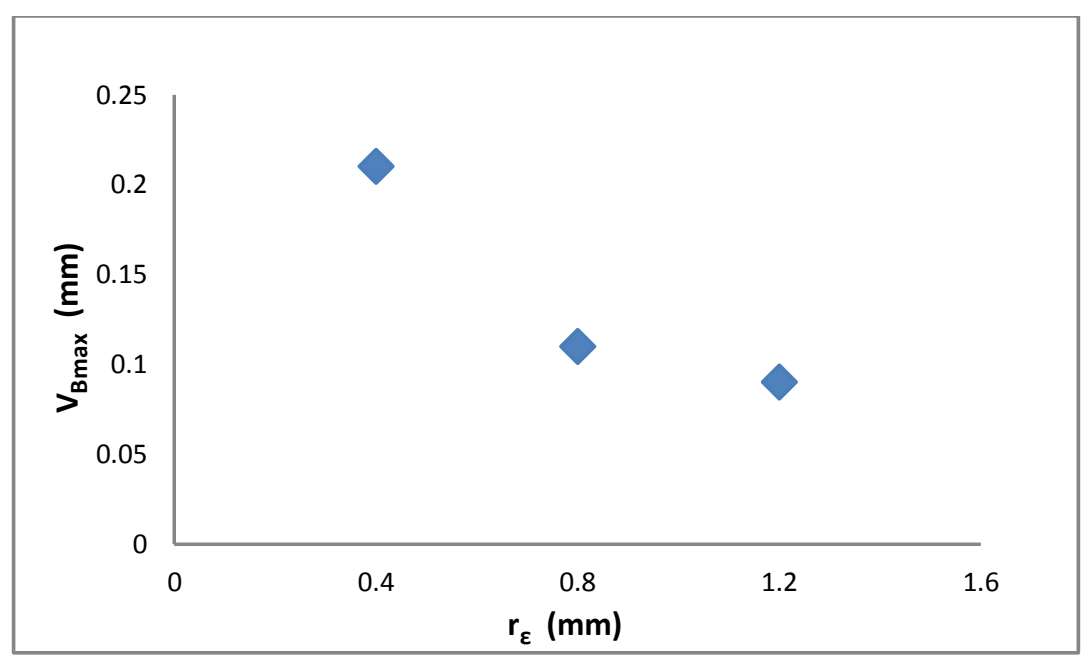

Fig. (6). The effect of the nose radius on the maximum flank wear ( $\mathrm{f}=0.08 \mathrm{~mm} / \mathrm{rev}, \mathrm{d}=0.5 \mathrm{~mm}, \mathrm{~N}=1000 \mathrm{rpm})$.

The analysis of the experiments revealed that the nose radius variation has no considerable effect on the dimensional accuracy. However, as shown in Fig. (5), it is clear that the best dimensional accuracy is obtained with $0.4 \mathrm{~mm}$ and 0.8 $\mathrm{mm}$ nose radii. Although the flank wear increases by decreasing the nose radius (see Fig. 6), the results show that the dimensional accuracy improves with decreasing the nose radius. This phenomenon reveals that the tool wear has no significant effect on the dimensional accuracy. As shown in Fig. (7), by increasing the nose radius, the generated vibration is increased significantly. This reveals that although the tool wear is exacerbated by decreasing the nose radius from 1.2 to $0.4 \mathrm{~mm}$, the dimensional accuracy is improved due to the lower produced vibration. The increase in the 
dimensional deviation at larger nose radius is due to the higher radial forces and vibration, which both occur due to the larger contact area between the workpiece and the cutting tool.

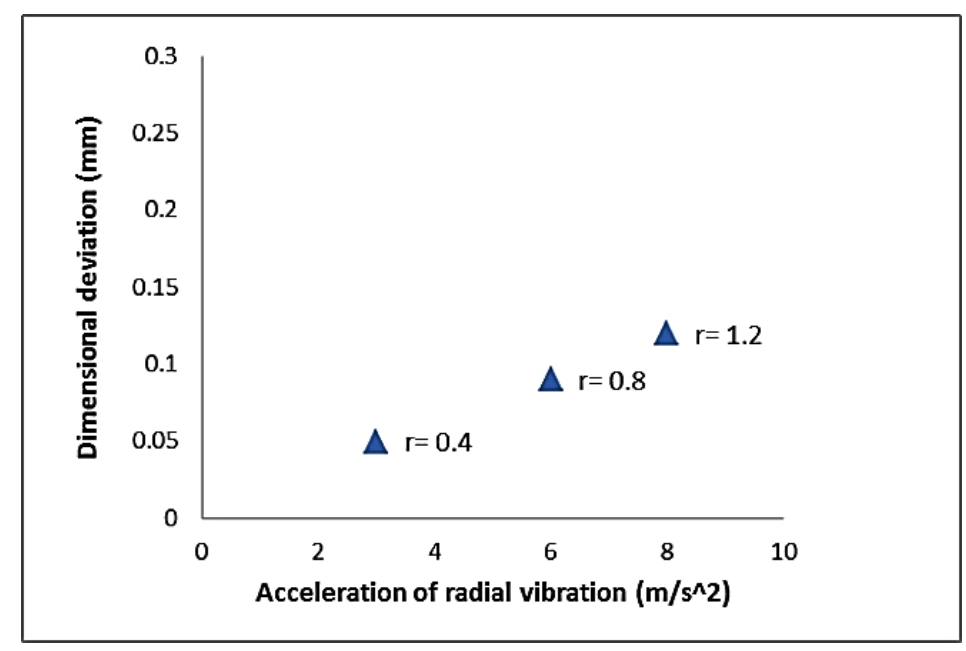

Fig. (7). The effect of vibration on the dimensional deviation at different nose radii ( $\mathrm{f}=0.16 \mathrm{~mm} / \mathrm{rev}, \mathrm{d}=0.5 \mathrm{~mm}, \mathrm{~N}=1000 \mathrm{rpm})$.

\subsection{The Effect of Feed Rate (f)}

As expected, the feed rate with a $50 \%$ contribution has the greatest effect on the $\mathrm{R}_{\mathrm{a}}$. The results of the experiments show that by increasing the feed speed from 0.08 to $0.32 \mathrm{~mm} / \mathrm{rev}$, the $\mathrm{R}_{\mathrm{a}}$ average increases from 1.4 to $5.9 \mu \mathrm{m}$. This deterioration of the surface roughness is mainly due to helicoid furrows, which generated because of the tool-workpiece relative movement. As the feed rate increases, the furrows become wider and deeper and subsequently increase the surface roughness. Moreover, as shown in Fig. (8), it was observed that the cutting forces are increased by increasing the feed rate. By increasing the feed rate, the cutting forces increase to create the required plastic deformation and therefore, extra heat is produced in the cutting zone. This generated heat increases the tool wear, and ultimately deteriorates the surface finish. Fig. (9) completely confirms this behavior. As the feed rate increases, the tool wear is increased and the surface finish is deteriorated subsequently. It was observed that for any level of the spindle speed, cutting depth, or even nose radius, the best $\mathrm{R}_{\mathrm{a}}$ is achieved at the lowest level of the feed rate. This behavior is completely compatible with the measured flank wear, because the lowest flank wear was observed at the lowest feed rate. Researchers reported similar results for both wiper and conventional ceramics and coated carbide tools [12, 14, 20], whereas for $\mathrm{Al}_{2} \mathrm{O}_{3}+\mathrm{TiCN}$ mixed ceramic tool, Aslan et al. [21] proposed the medium level of the feed speed to achieve the best surface quality for AISI4140 steel.

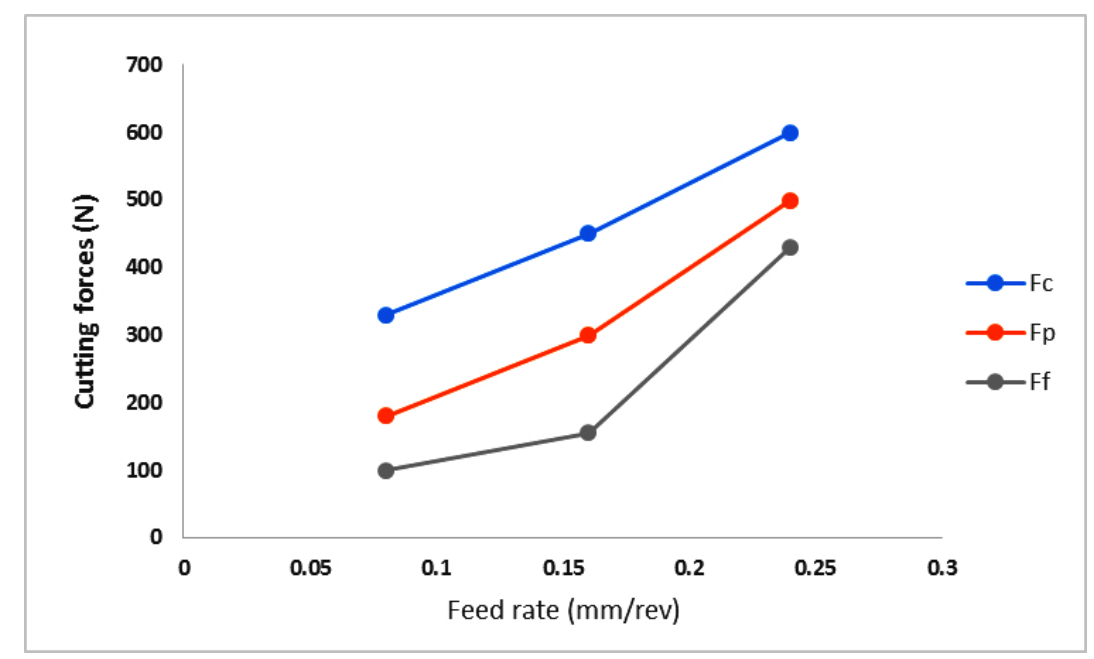

Fig. (8). The effect of feed rate on the cutting forces $\left(r_{\varepsilon}=0.8 \mathrm{~mm}, \mathrm{~d}=0.5 \mathrm{~mm}, \mathrm{~N}=1000 \mathrm{rpm}\right)$. 


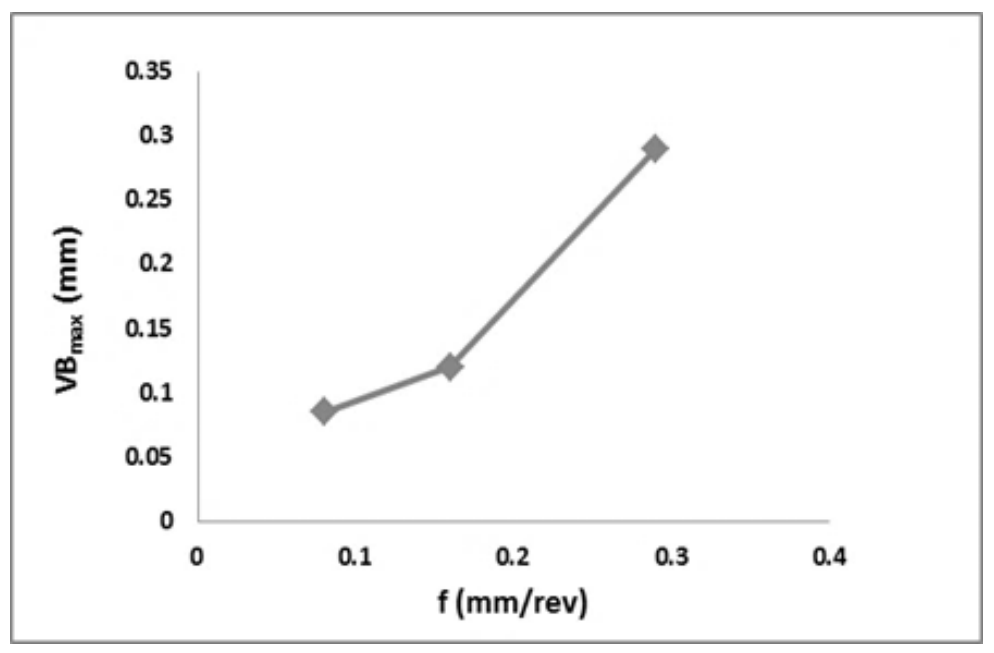

Fig. (9). The effect of feed rate on the maximum flank wear $\left(r_{\varepsilon}=1.2 \mathrm{~mm}, \mathrm{~d}=0.5 \mathrm{~mm}, \mathrm{~N}=2000 \mathrm{rpm}\right)$.

According to the experimental results, at the cutting depths of $2 \mathrm{~mm}$ and $3 \mathrm{~mm}$, when the feed rate gradually increases up to 0.32 , the $R_{a}$ values first increase until the highest value is reached at $0.16 \mathrm{~mm} / \mathrm{rev}$. Then, by further increasing the feed rate, the $\mathrm{R}_{\mathrm{a}}$ values decrease unexpectedly. This complicated behavior contradicts with the common expectation that the surface roughness always increases by increasing the feed rate. It is also interesting to note that at $\mathrm{r}_{\varepsilon}=0.4 \mathrm{~mm}$, when the feed rate increases from 0.16 to $0.32 \mathrm{~mm} / \mathrm{rev}$, the produced surface roughness decreases from 9.46 to $8 \mu \mathrm{m}$, while at $r_{\varepsilon}=0.8$ and $1.2 \mathrm{~mm}$ no strange behavior was seen. Therefore, it can be concluded that the influence of the feed rate on the surface roughness variations, particularly at high feed rates strongly depends on the insert nose radius size.

Analyzing the literature about studying the hard turning also revealed that most of the researchers have used feed speeds in the range of 0.04 to $0.36 \mathrm{~mm} / \mathrm{rev}$ in their experiments. Table 3 summarizes the ranges of the feed rate that various researchers used for studying the surface roughness evolution in the hard turning. Their results suggest that the surface roughness is deteriorated by increasing the feed rate within the range of 0.04 to $0.36 \mathrm{~mm} / \mathrm{rev}$. However, in the current research, the obtained results showed that increasing the feed rate from a particular value not only leads to no significant changes in the surface roughness value but in some cases can also decrease the surface roughness. This subject is important, especially in situations, where the time or the cost of the operation is more crucial than the surface finish. It is well known that strain hardening and thermal softening are two important factors in the machining that significantly affect the operational final quality. The two conflicting factors act opposite to each other. Strain hardening increases the hardness of the workpiece material and the thermal softening reduces the material's hardness. At the feed rate relatively higher than $0.16 \mathrm{~mm} / \mathrm{rev}($ e.g. $0.3 \mathrm{~mm} / \mathrm{rev}$ ), due to higher thrust force (Fig. 8), extra heat is generated compared with the lower feed rate. The produced heat leads to thermal softening of the material. On the other hand, CBN tools have an excellent hot hardness and the produced heat overcomes the strain hardening effects of the workpiece material and decreases its hardness and shear strength, especially at the interface of the workpiece and tool. Thus, the thermal softening of the workpiece material reduces the wear rate and therefore, the surface roughness is not increased.

Table 3. The range of feed rates used by researchers for studying $R_{a}$ in the hard turning.

\begin{tabular}{|c|c|c|c|}
\hline Reference & Type of insert & Material & Feed rate range (mm/rev) \\
\hline$[$ Lalwani et al. $]$ & Coated Ceramic & MDN250 & $0.04-0.12$ \\
\hline$[$ Ding et al. $]$ & CBN & AISI 52100 & $0.05-0.12$ \\
\hline$[$ Agrawal et al. $]$ & CBN & AISI 4340 & $0.08-0.15$ \\
\hline$[$ Singh et al. $]$ & Ceramic & AISI 52100 & $0.1-0.32$ \\
\hline$[$ Akkuş et al. $]$ & Coated carbide & AISI 4140 & $0.18-0.36$ \\
\hline$[$ Asiltürk et al. $]$ & Coated carbide & AISI 4140 & $0.18-0.36$ \\
\hline$[$ Elbah et al. $]$ & Wiper and conventional Ceramic & AISI 4140 & $0.08-0.14$ \\
\hline$[$ Kiran et al. $]$ & Coated carbide & ST 174PH, ST 12TE, ST T1/13W & $0.08-0.24$ \\
\hline$[$ Singh et al. $]$ & Ceramic & AISI 52100 & $0.1-0.32$ \\
\hline
\end{tabular}


(Table $\square$ ) contd.....

\begin{tabular}{|c|c|c|c|}
\hline Reference & Type of insert & Material & Feed rate range $(\mathrm{mm} / \mathrm{rev})$ \\
\hline [Özel et al.] & $\mathrm{CBN}$ & AISI H13 & $0.1-0.2$ \\
\hline [Khrais et al.] & Cemented carbide & AISI 4140 & 0.14 (constant) \\
\hline [Das et al.] & Coated Ceramic & AISI 4140 & $0.05-0.15$ \\
\hline $\begin{array}{c}{[\text { Aslan et al. }]} \\
{[\text { Ferreira et al. }]}\end{array}$ & $\begin{array}{l}\text { Coated Ceramic } \\
\text { Coated Ceramic }\end{array}$ & $\begin{array}{l}\text { AISI } 4140 \\
\text { AISI H13 } \\
\end{array}$ & $\begin{array}{l}0.05-0.2 \\
0.05-0.4\end{array}$ \\
\hline [Aouici et al.] & $\mathrm{CBN}$ & X38CrMoV5-1 steel & $0.08-0.16$ \\
\hline [Kumar et al.] & Ceramic & EN 24 steel & 0.12 (constant) \\
\hline [Liu et al.] & $\mathrm{CBN}$ & JIS SUJ2 & 0.1 (constant) \\
\hline [Revel et al.] & $\mathrm{CBN}$ & AISI 52100 & $0.05-0.1$ \\
\hline [Sharman et al.] & Coated tungsten carbide & Inconel $718^{\mathrm{TM}}$ & $0.25-0.5$ \\
\hline [Huang et al.] & $\mathrm{CBN}$ & 52100 bearing steel & $0.07-0.15$ \\
\hline [Ahmari et al.] & Carbide & AISI 302 & $0.1-0.3$ \\
\hline [Lima et al.] & Coated carbide & AISI 4340, AISI D2 & $0.1-0.3$ \\
\hline [Chou et al.] & $\mathrm{CBN}$ & AISI 52100 & 0.01 (constant) \\
\hline [Aouici et al.] & $\mathrm{CBN}$ & AISI H11 steel & $0.08-0.16$ \\
\hline [Çydaş et al.] & CBN, Carbide, Ceramic & AISI 4340 & $0.08-0.24$ \\
\hline [Çydaş et al.] & Coated carbide & AISI 4340 & $0.1-0.26$ \\
\hline [Çydaş et al.] & Ceramic & AISI D2 & $0.05-0.15$ \\
\hline $\begin{array}{c}\text { [Çydaş et al.] } \\
\text { [Dogra et al.] } \\
\text { [Mondal et al.] } \\
\text { [Qin et } \text { al.] } \\
\text { [Qin } \text { et } \text { al. }]\end{array}$ & $\begin{array}{c}\text { CBN } \\
\text { CBN } \\
\text { TiC coated carbide } \\
\text { PCBN } \\
\text { CBN }\end{array}$ & $\begin{array}{c}\text { EN } 31 \\
\text { AISI } 8620 \text { steel } \\
16 \mathrm{MnCrS5} \\
40 \mathrm{Cr} \text { steel } \\
\text { AISI } 1053 \text { - AISI } 1070\end{array}$ & $\begin{array}{r}0.075-0.15 \\
0.08 \\
0.06-0.1 \\
0.08 \\
-\end{array}$ \\
\hline
\end{tabular}

As illustrated in Fig. (10), the effect of the feed rate on the dimensional accuracy is completely different. The experimental results showed that when the feed rate is gradually increased from 0.08 to 0.32 , the dimensional deviation first decreases unexpectedly until the lowest value is achieved at $0.16 \mathrm{~mm} / \mathrm{rev}$, then by further increasing the feed $(0.16$ to $0.32 \mathrm{~mm} / \mathrm{rev}$ ), the dimensional deviation increases significantly. Some researchers also reported this unexpected improvement of the dimensional accuracy in the conventional turning when the feed rate increases up to a certain value. It seems that at very low feed rates (e.g. $0.08 \mathrm{~mm} / \mathrm{rev})$, the tool instead of cutting the chips by shearing action, simply rides over and burnishes the machining surface and decreases the dimensional accuracy. When the feed rate increases up to a certain value (e.g. $0.16 \mathrm{~mm} / \mathrm{rev}$ ), the chip removal action is improved and the dimensional deviation is decreased. On the other hand, at the higher feed rates (e.g. $0.32 \mathrm{~mm} / \mathrm{rev})$, the feed negative effects become dominant and start decreasing the dimensional accuracy. As discussed earlier, the high cutting forces and vibration lead to the dimensional accuracy deterioration. The experimental results showed that almost in all cases, $0.16 \mathrm{~mm} / \mathrm{rev}$ produces the best dimensional accuracy.

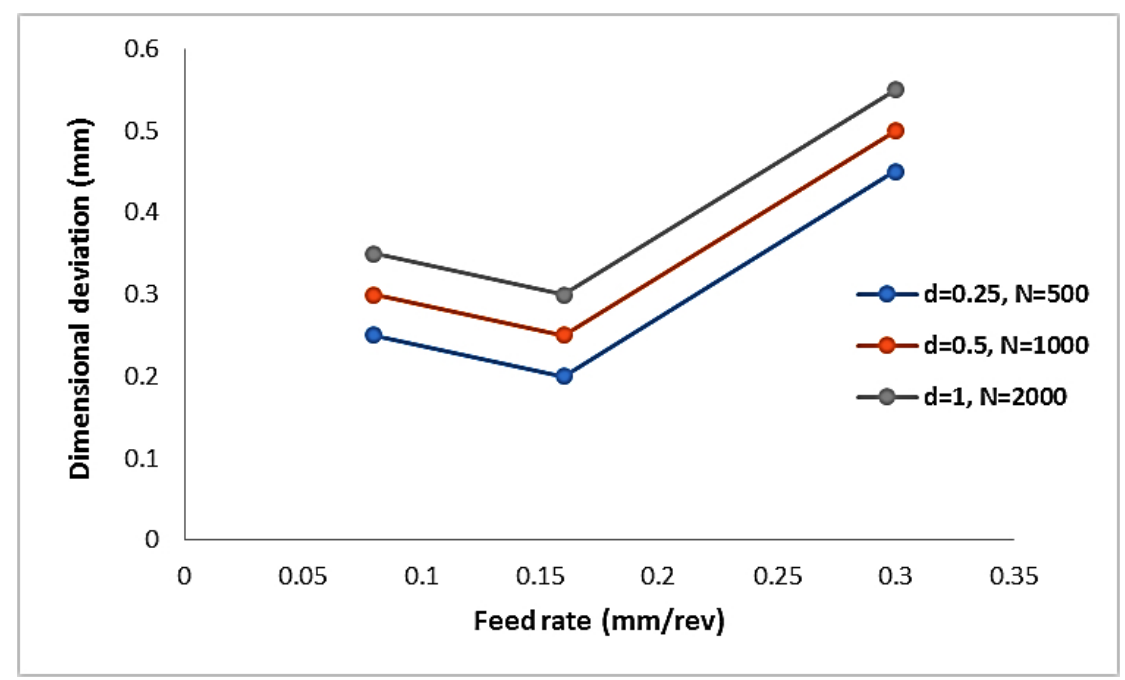

Fig. (10). The effect of feed rate on the dimensional deviation at different cutting conditions $\left(r_{\varepsilon}=0.8 \mathrm{~mm}\right)$. 


\subsection{The Effect of Cutting Depth (d)}

The effect of cutting depth on the surface finish variations is negligible. Researchers reported similar result by using coated carbide and mixed ceramic inserts [12, 20, 21]. However, M. Elbah et al. [14] reported that for wiper ceramic inserts, the surface roughness is affected significantly by varying the cutting depth. Increasing the cutting depth to $2 \mathrm{~mm}$ improves the surface roughness about $15 \%$. On the other hand, further increase in the cutting depth (i.e. $\mathrm{d}=3 \mathrm{~mm}$ ) leads to the surface roughness degradation. The surface roughness degradation mainly is due to the chatter that usually occurs at high cutting depths. According to the experimental results, $0.202 \mu \mathrm{m}$ is the best surface roughness that has been obtained at $\mathrm{r}_{\varepsilon}=1.2 \mathrm{~mm}, \mathrm{~d}=0.5 \mathrm{~mm}, \mathrm{~N}=2000 \mathrm{rpm}$, and $\mathrm{f}=0.08 \mathrm{~mm} / \mathrm{rev}$. From Table 2, it is obvious the obtained surface roughness of 0.202 is the best value that has been reported in the hard turning of AISI4140 steel until now. This great surface finish is comparable with the surface quality obtained by the conventional grinding operations. In addition, the obtained results proved that CBN cutting tools produce a better surface finish at both higher cutting depth and speed compared with the ceramic and coated carbide inserts. Therefore, by using CBN inserts during the finish hard turning, the cost and the time of the operation both will reduce significantly. Researchers proposed that during the finish hard turning, the cutting depth must be selected in the range of $0.1-0.3 \mathrm{~mm}[27,38]$. The results prove that by selecting the CBN cutting tool, a higher cutting depth can be selected for the operation compared with the other cutting tools.

The effect of the cutting depth on the dimensional accuracy is different from its effect on the surface finish. The results showed that the cutting depth is the most important factor affecting the dimensional accuracy. As shown in Fig. (11), the dimensional deviation increases drastically by increasing the cutting depth. The experiments show that the best dimensional accuracy is always obtained at the lowest level of the cutting depth. This is related to the lower level of the vibration at the low cutting depth, which finally improves the dimensional accuracy. As shown in Fig. (12), when the cutting depth increases, the produced vibration is increased and finally, this higher vibration deteriorates the surface finish. This subject has to be considered in the final pass, particularly at finish hard turning. It should be noticed that if the effect of cutting depth on the dimensional accuracy is not considered, an additional cutting pass has to be applied to achieve the desired diameter size and this matter will finally increase the total operational time and cost.

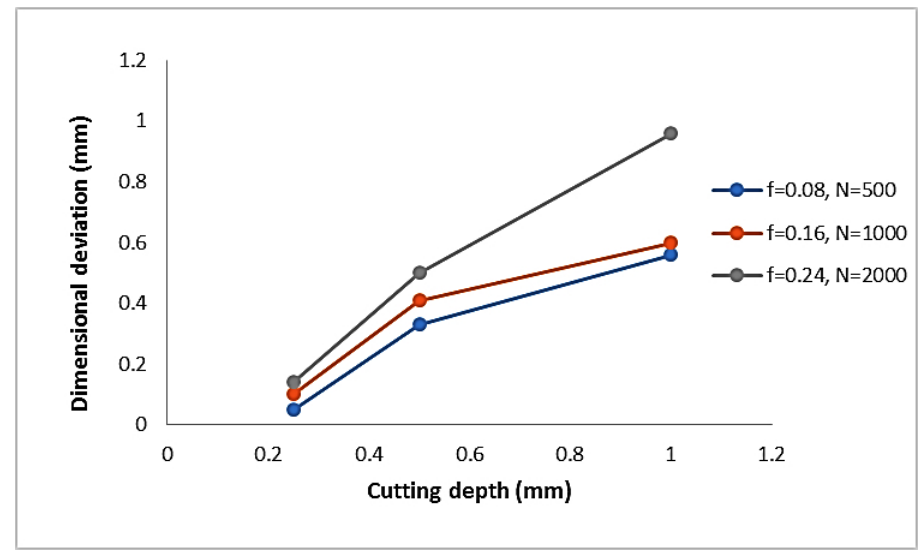

Fig. (11). The variations of the dimensional deviation under different cutting depths $\left(\mathrm{r}_{\varepsilon}=0.8 \mathrm{~mm}\right)$.

The analysis of contour and 3D surface plots usually is used to find the optimal machining condition. The analysis results revealed that a good surface roughness $\left(R_{a} \leq 2 \mu \mathrm{m}\right)$ can be achieved for any level of the cutting depth, when the feed rate is lower than $0.1 \mathrm{~mm} / \mathrm{rev}$ and the spindle speed is higher than $750 \mathrm{rpm}$. It can be seen from Fig. (13) that the worst values of the surface roughness are obtained at the lowest level of the spindle speed and nose radius. For any level of the insert nose radius, the zone where a good surface finish can be obtained is limited to the lowest feed rate. For the nose radius larger than $0.8 \mathrm{~mm}$, this zone is wider than that of the smaller nose radius. Hence, a greater feed rate can be selected with a larger nose radius, which may result in high good surface quality and material removal rate simultaneously. The effect of nose radius and cutting depth on the surface roughness is represented in Figs. (13i-j). According to the figure, the moderate level of the cutting depth yields an appropriate surface finish. As shown in Figs. (13k-l), a better surface quality is achieved when the spindle speed and nose radius are higher than their moderate level. From the above discussion, it can be concluded that in the dry hard turning operation with CBN inserts, the highest level of the spindle speed and nose radius, along with the moderate level of the cutting depth and the lowest level of the feed rate, is an ideal combination to achieve an acceptable surface finish. 


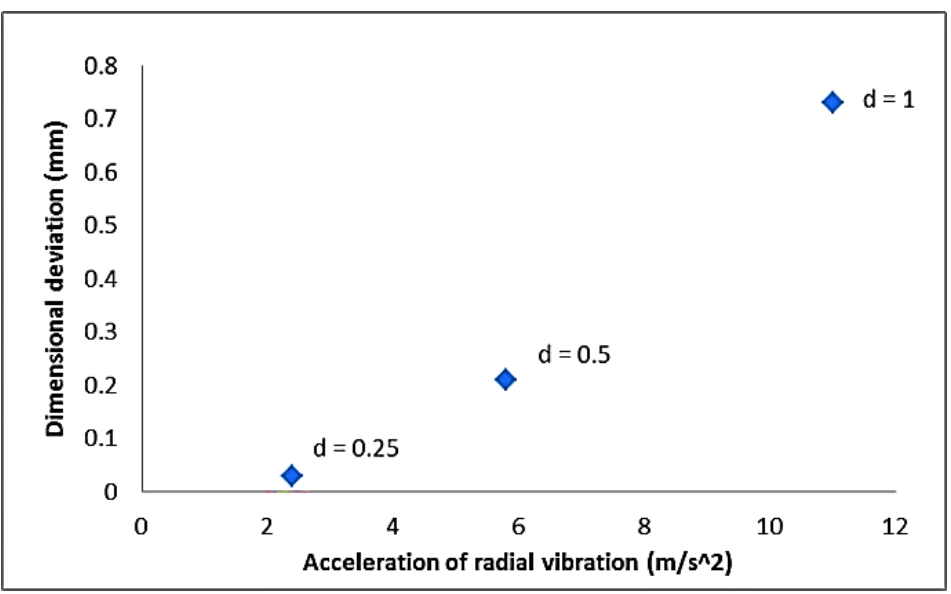

Fig. (12). The effect of vibration on the dimensional accuracy at different cutting depths $\left(\mathrm{f}=0.16 \mathrm{~mm} / \mathrm{rev}, \mathrm{r}_{\varepsilon}=0.8 \mathrm{~mm}, \mathrm{~N}=1000 \mathrm{rpm}\right)$.
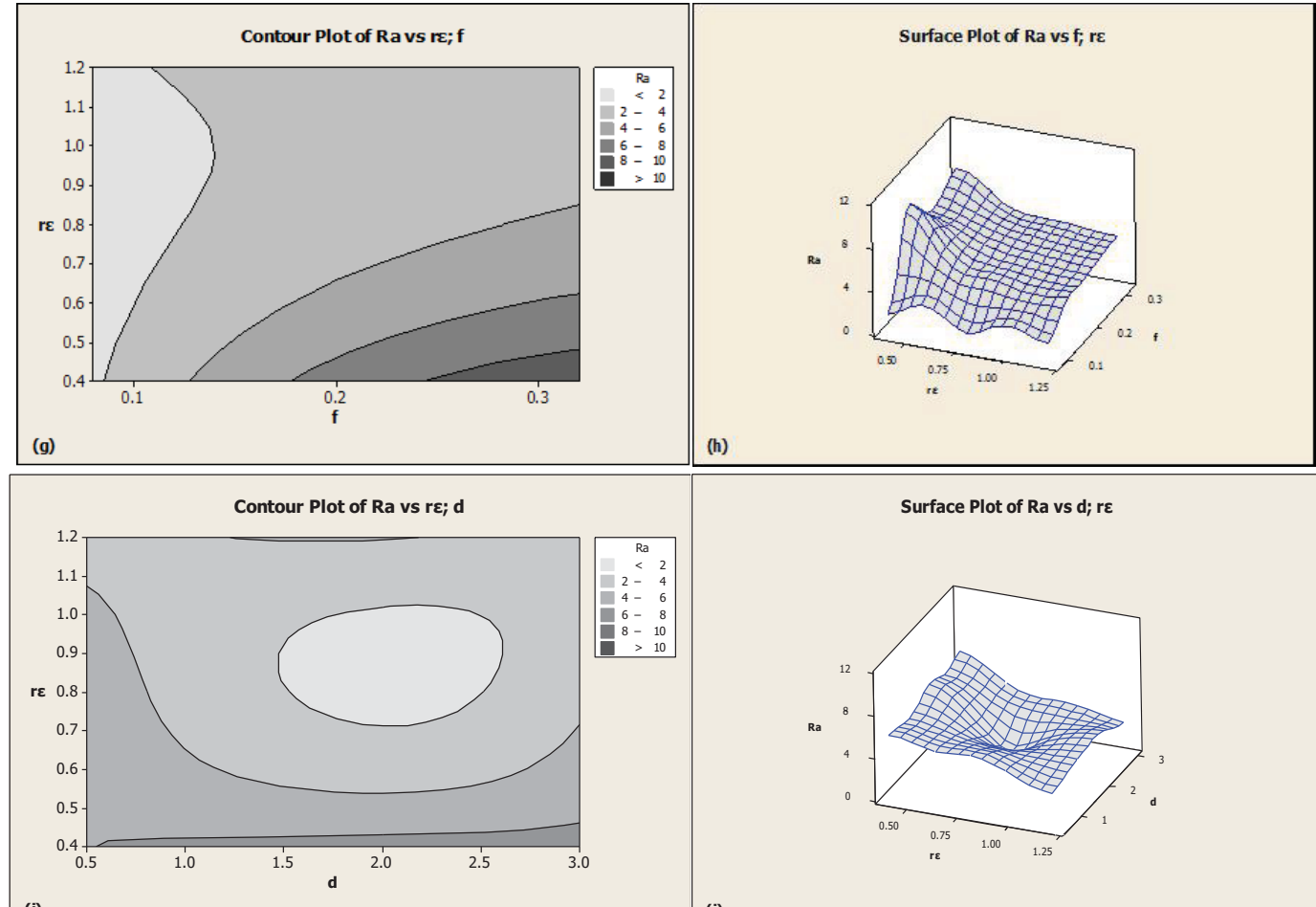

(i)
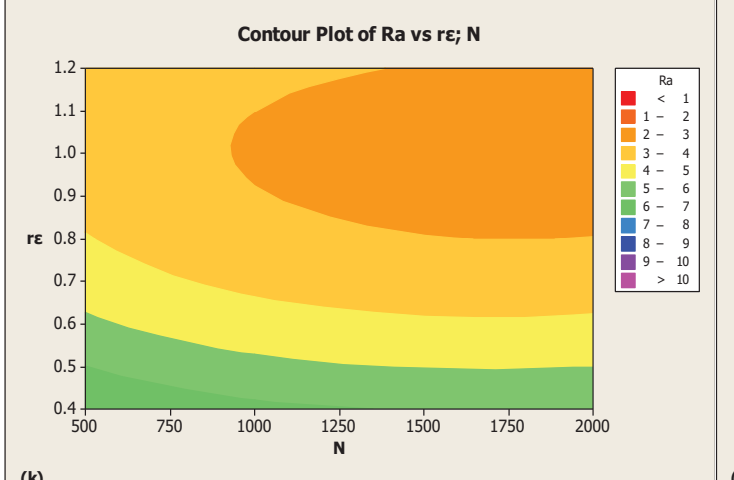

Surface Plot of Ra vs re; N

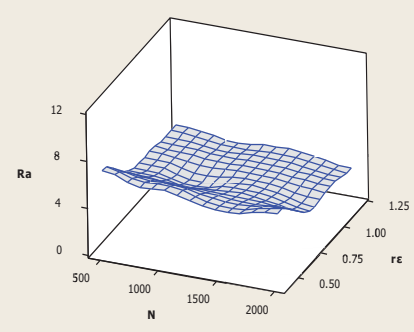

(L)

Fig. (13). Contour and 3D surface plots for the processing parameters effect on surface roughness $\left(\mathrm{R}_{\mathrm{a}}\right)$. 
It is obvious that the best dimensional accuracy is obtained when the dimensional deviation is equal to zero (i.e. $\Delta \mathrm{d}=0$ ). Studying the analysis results revealed that a good dimensional accuracy is obtained at the lowest level of the spindle speed and nose radius, which is clearly depicted in Figs. (14a-b). In addition, as indicated in Figs. (14c-d), the spindle speed between 600 to $1100 \mathrm{rpm}$ along with the feed rate lower than $0.12 \mathrm{~mm} / \mathrm{rev}$ are an ideal combination to achieve a good dimensional accuracy. It can be seen from Figs. (14g to $\mathbf{j})$ that for any level of the feed rate and spindle speed, the best dimensional accuracy is achieved at the cutting depth lower than $1 \mathrm{~mm}$.
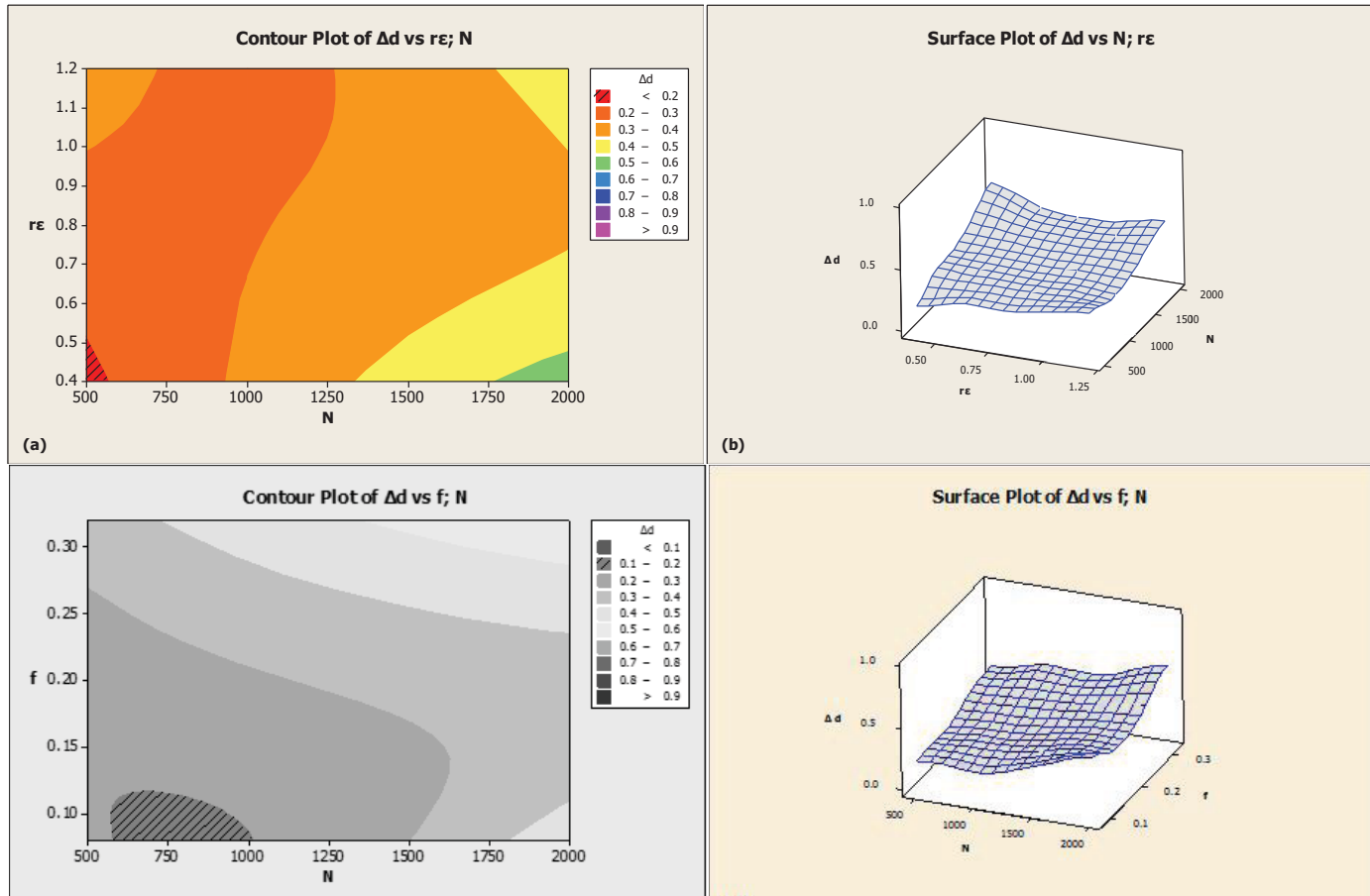

(c)

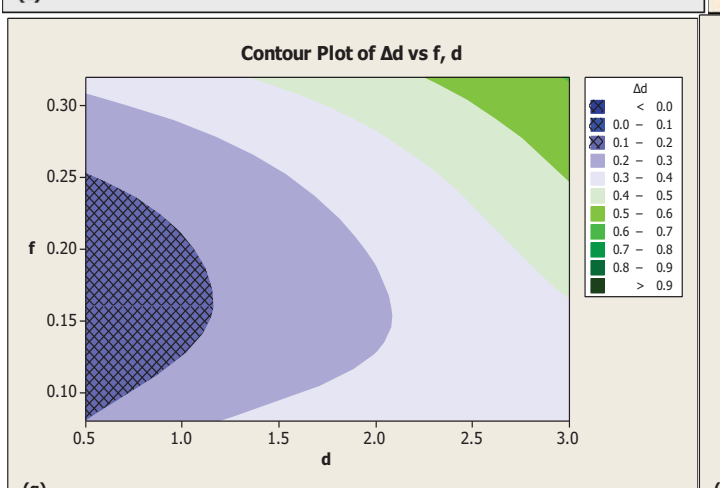

(g)

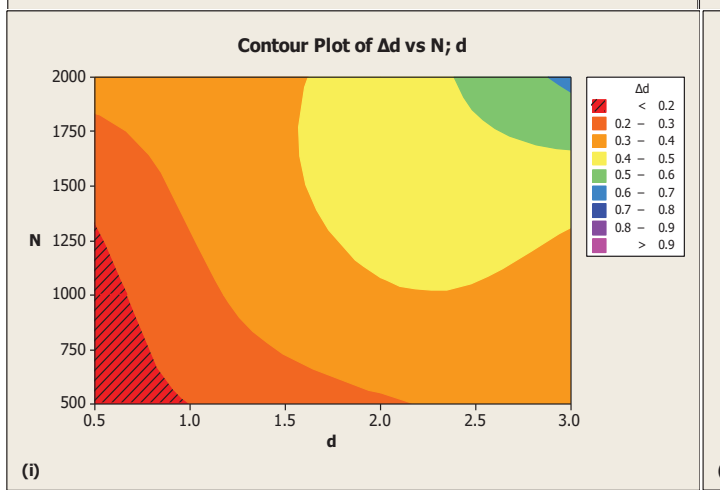

Surface Plot of $\Delta d v s$; $N$

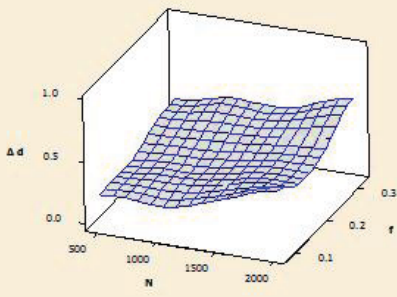

(d)

Surface Plot of $\Delta d$ vs $f ; d$

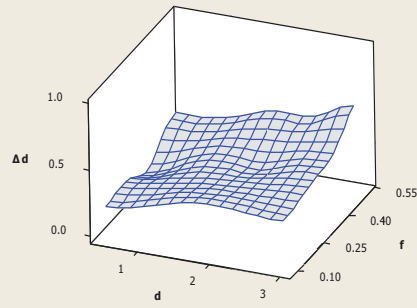

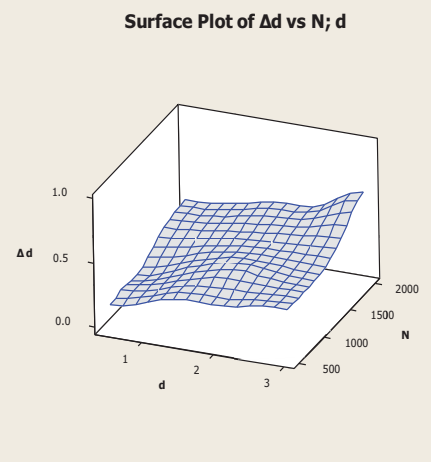

Fig. (14). Contour and 3D surface plots for the effect of processing parameters on dimensional deviation $(\Delta d)$. 
According to the experimental results, $0.5 \mathrm{~mm}$ cutting depth, $0.8 \mathrm{~mm}$ nose radius, $0.16 \mathrm{~mm} / \mathrm{rev}$ feed rate, and the speed lower than $1100 \mathrm{rpm}$, provide the best dimensional accuracy. Therefore, it can be concluded that the best dimensional accuracy is achieved with the lowest level of the cutting depth, the moderate level of the feed rate and nose radius and also the moderate or lowest level of the spindle speed.

\section{CONCLUSION}

In this study, the effect of processing parameters on the dimensional accuracy and surface roughness of hardened steel with CBN cutting tools was investigated under the dry condition. Then, the effect of vibration, cutting forces, and tool wear on the dimensional accuracy and surface roughness was studied experimentally. The results showed that feed rate has the most important influence on the surface roughness, whereas spindle speed and cutting depth have no considerable effect. On the other hand, cutting depth and spindle speed have the greatest effect on the dimensional accuracy, while nose radius has no considerable effect. The vibration and wear analysis revealed that tool wear compared with the vibration has no considerable effect on the dimensional accuracy. It was also observed that the spindle speed has a contradictory effect on the surface quality and dimensional accuracy. According to the experimental results, $0.5 \mathrm{~mm}$ cutting depth, $0.16 \mathrm{~mm} / \mathrm{rev}$ feed rate, and the speed lower than $1100 \mathrm{rpm}$, provided the best dimensional accuracy. CBN cutting tool produces a better surface roughness at both higher cutting speed and cutting depth compared with the ceramic and coated carbide inserts. In addition, by using CBN cutting tool higher cutting depths can be used compared to the recommended range of 0.1-0.3 mm for finish hard turning. The obtained results showed that increasing the feed rate from a particular value not only leads to no significant changes in the surface roughness value but in some cases can also decreases the surface roughness. The combination of the highest level of spindle speed and nose radius, along with moderate cutting depth and the lowest level of feed rate is ideal to achieve the best surface roughness. The best surface roughness of $0.202 \mu \mathrm{m}$ was obtained at the nose radius of $1.2 \mathrm{~mm}$, the spindle speed of $2000 \mathrm{rpm}$, the feed rate of $0.08 \mathrm{~mm} / \mathrm{rev}$ and $0.5 \mathrm{~mm}$ cutting depth, which is comparable with the surface quality obtained by the conventional grinding.

\section{CONSENT FOR PUBLICATION}

Not applicable.

\section{CONFLICTS OF INTEREST}

The authors declare no conflict of interest, financial, or otherwise.

\section{ACKNOWLEDGEMENTS}

Declared none.

\section{REFERENCES}

[1] A. Ginting, R. Skein, D. Cuaca, and Z. Masyithah, "The characteristics of CVD-and PVD-coated carbide tools in hard turning of AISI 4340", Measurement, vol. 129, pp. 548-557, 2018. [http://dx.doi.org/10.1016/j.measurement.2018.07.072]

[2] H. Ding, and Y.C. Shin, "Multi-physics modelling and simulations of surface microstructure alteration in hard turning", J. Mater. Process. Technol., vol. 213, pp. 877-886, 2013.

[http://dx.doi.org/10.1016/j.jmatprotec.2012.12.016]

[3] A. Agrawal, S. Goel, W.B. Rashid, and M. Price, "Prediction of surface roughness during hard turning of AISI 4340 steel (69 HRC)", Appl. Soft Comput., vol. 30, pp. 279-286, 2015. [http://dx.doi.org/10.1016/j.asoc.2015.01.059]

[4] M.A. Shalaby, M.A. El Hakim, and S.C. Veldhuis, "A thermal model for hard precision turning", Int. J. Adv. Manuf. Technol., vol. 98, no. 9-12, pp. 2401-2413, 2018. [http://dx.doi.org/10.1007/s00170-018-2389-8]

[5] H. Akkuş, and İ. Asilturk, "Predicting surface roughness of AISI 4140 steel in hard turning process through artificial neural network, fuzzy logic and regression models", Sci. Res. Essays, vol. 16, pp. 2729-2736, 2011.

[6] S. Saini, A. Inderpreet, and S. Vishal, "Residual stresses, surface roughness, and tool wear in hard turning: A comprehensive review", Mater. Manuf. Process., vol. 27, pp. 583-598, 2012. [http://dx.doi.org/10.1080/10426914.2011.585505]

[7] Sandvik coromant, 2010, Metal working products - General turning. AB Sandvik Coromant, Sandvik Automation GmbH, Viernheim. 
[8] A. Panda, A.K. Sahoo, A.K. Rout, R. Kumar, and R.K. Das, "Investigation of flank wear in hard turning of AISI 52100 grade steel using multilayer coated carbide and mixed ceramic inserts", Procedia Manufacturing, vol. 20, pp. 365-371, 2018. [http://dx.doi.org/10.1016/j.promfg.2018.02.053]

[9] S.I. Kim, Y. Lee, and S.M. Byon, "Study on constitutive relation of AISI 4140 steel subject to large strain at elevated temperatures", J. Mater. Process. Technol., vol. 140, pp. 84-89, 2003. [http://dx.doi.org/10.1016/S0924-0136(03)00742-8]

[10] J. Zhang, and S.Y. Liang, "Process optimization of finish turning of hardened steels", Mater. Manuf. Process., vol. 22, pp. $107-113,2007$. [http://dx.doi.org/10.1080/10426910601016020]

[11] C. Ahilan, S. Kumanan, N. Sivakumaran, and J.E.R. Dhas, "Modelling and prediction of machining quality in the CNC turning process using intelligent hybrid decision making tools", Appl. Soft Comput., vol. 13, pp. 1543-1551, 2013.

[http://dx.doi.org/10.1016/j.asoc.2012.03.071]

[12] I. Asiltürk, and H. Akkuş, "Determining the effect of cutting parameters on surface roughness in hard turning using the Taguchi method", Measurement, vol. 44, pp. 1697-1704, 2011.

[13] H. Gökkaya, and M. Nalbant, "The effects of cutting tool geometry and processing parameters on the surface roughness of AISI 1030 steel", Mater. Des., vol. 28, pp. 717-721, 2007.

[http://dx.doi.org/10.1016/j.matdes.2005.09.013]

[14] M. Elbah, M.A. Yallese, H. Aouici, T. Mabrouki, and J.F. Rigal, "Comparative assessment of wiper and conventional ceramic tools on surface roughness in hard turning AISI 4140 steel", Measurement, vol. 46, pp. 3041-3056, 2011. [http://dx.doi.org/10.1016/j.measurement.2013.06.018]

[15] C.P. Kiran, and S. Clement, "Surface quality investigation of turbine blade steels for turning process", Measurement, vol. 46, pp. 1875-1895, 2013.

[http://dx.doi.org/10.1016/j.measurement.2012.12.022]

[16] D. Singh, and P. Venkateswara Rao, "Optimization of tool geometry and cutting parameters for hard turning", Mater. Manuf. Process., vol. 22, pp. 15-21, 2007.

[http://dx.doi.org/10.1080/10426910601015816]

[17] T. Özel, and Y. Karpat, "Predictive modelling of surface roughness and tool wear in hard turning using regression and neural networks", Int. J. Mach. Tools Manuf., vol. 45, pp. 467-479, 2005. [http://dx.doi.org/10.1016/j.ijmachtools.2004.09.007]

[18] S.Z.T. Chavoshi, "M. Surface roughness modelling in the hard turning operation of AISI 4140 using CBN cutting tool", Int. J. Mater. Form., vol. 3, pp. 233-239, 2010.

[http://dx.doi.org/10.1007/s12289-009-0679-2]

[19] S.K. Khrais, and Y.J. Lin, "Wear mechanisms and tool performance of TiAlN PVD coated inserts during machining of AISI 4140 steel", Wear, vol. 262, pp. 64-69, 2007. [http://dx.doi.org/10.1016/j.wear.2006.03.052]

[20] S.R. Das, D. Dhupal, and A. Kumar, "Experimental investigation into machinability of hardened AISI 4140 steel using TiN coated ceramic tool", Measurement, vol. 62, pp. 108-126, 2015. [http://dx.doi.org/10.1016/j.measurement.2014.11.008]

[21] E. Aslan, N. Camuşcu, and B. Birgören, "Design optimization of cutting parameters when turning hardened AISI 4140 steel (63 HRC) with Al 2 O 3+ TiCN mixed ceramic tool", Mater. Des., vol. 28, pp. 1618-1622, 2007.

[http://dx.doi.org/10.1016/j.matdes.2006.02.006]

[22] R. Ferreira, D. Carou, C.H. Lauro, and J.P. Davim, "Surface roughness investigation in the hard turning of steel using ceramic tools", Mater. Manuf. Process., vol. 31, pp. 648-652, 2016. [http://dx.doi.org/10.1080/10426914.2014.995051]

[23] D.C. Montgomery, Design and Analysis of Experiments., $5^{\text {th }}$ ed John Wiley \& Sons Inc, 2001.

[24] H. Aouici, M.A. Yallese, B. Fnides, K. Chaoui, and T. Mabrouki, "Modeling and optimization of hard turning of X38CrMoV5-1 steel with CBN tool: Machining parameters effects on flank wear and surface roughness", Journal of mechanical science and technology, vol. 25, pp. 2843-2851, 2011.

[25] A.S. Kumar, A.R. Durai, and T. Sornakumar, "Machinability of hardened steel using alumina based ceramic cutting tools", Int. J. Refract. Met. Hard Mater., vol. 21, pp. 109-117, 2003. [http://dx.doi.org/10.1016/S0263-4368(03)00004-0]

[26] M. Liu, J.I. Takagi, and A. Tsukuda, "Effect of tool nose radius and tool wear on residual stress distribution in hard turning of bearing steel", J. Mater. Process. Technol., vol. 150, pp. 234-241, 2004. [http://dx.doi.org/10.1016/j.jmatprotec.2004.02.038]

[27] P. Revel, N. Jouini, G. Thoquenne, and F. Lefebvre, "High precision hard turning of AISI 52100 bearing steel", Precis. Eng., vol. 43, pp. 24-33, 2016.

[http://dx.doi.org/10.1016/j.precisioneng.2015.06.006] 
[28] A.R.C. Sharman, J.I. Hughes, and K. Ridgway, "The effect of tool nose radius on surface integrity and residual stresses when turning Inconel 718 [http://dx.doi.org/10.1016/j.jmatprotec.2014.09.002]

[29] Y. Huang, and S.Y. Liang, "Effect of cutting conditions on tool performance in CBN hard turning", J. Manuf. Process., vol. 7, pp. 10-16, 2005 . [http://dx.doi.org/10.1016/S1526-6125(05)70077-3]

[30] A.M.A. Al-Ahmari, "Predictive machinability models for a selected hard material in turning operations", J. Mater. Process. Technol., vol. 190, pp. 305-311, 2007.

[http://dx.doi.org/10.1016/j.jmatprotec.2007.02.031]

[31] J.G. Lima, R.F. Avila, A.M. Abrao, M. Faustino, and J.P. Davim, "Hard turning: AISI 4340 high strength low alloy steel and AISI D2 cold work tool steel", J. Mater. Process. Technol., vol. 169, pp. 388-395, 2005. [http://dx.doi.org/10.1016/j.jmatprotec.2005.04.082]

[32] Y.K. Chou, C.J. Evans, and M.M. Barash, "Experimental investigation on cubic boron nitride turning of hardened AISI 52100 steel", J. Mater. Process. Technol., vol. 134, pp. 1-9, 2003. [http://dx.doi.org/10.1016/S0924-0136(02)00070-5]

[33] H. Aouici, M.A. Yallese, K. Chaoui, T. Mabrouki, and J.F. Rigal, "Analysis of surface roughness and cutting force components in hard turning with CBN tool: Prediction model and cutting conditions optimization", Measurement, vol. 45, pp. 344-353, 2012. [http://dx.doi.org/10.1016/j.measurement.2011.11.011]

[34] U. Çydaş, "Machinability evaluation in hard turning of AISI 4340 steel with different cutting tools using statistical techniques", Proc. Inst. Mech. Eng., B J. Eng. Manuf., vol. 224, pp. 1043-1055, 2010. [http://dx.doi.org/10.1243/09544054JEM1822]

[35] R. Suresh, S. Basavarajappa, and G.L. Samuel, "Some studies on hard turning of AISI 4340 steel using multilayer-coated carbide tool", Measurement, vol. 45, pp. 1872-1884, 2012.

[http://dx.doi.org/10.1016/j.measurement.2012.03.024]

[36] T. Özel, Y. Karpat, L. Figueira, and J.P. Davim, "Modelling of surface finish and tool flank wear in turning of AISI D2 steel with ceramic wiper inserts", J. Mater. Process. Technol., vol. 189, pp. 192-198, 2007. [http://dx.doi.org/10.1016/j.jmatprotec.2007.01.021]

[37] G. Bartarya, and S.K. Choudhury, "Influence of machining parameters on forces and surface roughness during finish hard turning of EN 31 steel", Proc. Inst. Mech. Eng., B J. Eng. Manuf., vol. 228, pp. 1068-1080, 2014. [http://dx.doi.org/10.1177/0954405413500492]

[38] G. Bartarya, and S.K. Choudhury, "State of the art in hard turning", Int. J. Mach. Tools Manuf., vol. 53, pp. 1-14, 2012. [http://dx.doi.org/10.1016/j.ijmachtools.2011.08.019]

[39] Y.K. Chou, and H. Song, "Tool nose radius effects on finish hard turning", J. Mater. Process. Technol., vol. 148, pp. 259-268, 2004. [http://dx.doi.org/10.1016/j.jmatprotec.2003.10.029]

[40] M. Dogra, V.S. Sharma, A. Sachdeva, and N.M. Suri, "Finish hard turning of continuous and interrupted surfaces with cubic boron nitride (CBN) and coated carbide tools", Mater. Manuf. Process., vol. 27, pp. 523-530, 2012. [http://dx.doi.org/10.1080/10426914.2011.593238]

[41] K. Mondal, S. Das, B. Mandal, and D. Sarkar, "An Investigation on Turning Hardened Steel using different tool inserts. Materials and Manufacturing Processes, (just accepted)",

[42] M.Y. Qin, B.Y. Ye, L.F. Liu, and A.D. He, "Investigation of Pre-stress hard turning of 40Cr Steel", Mater. Manuf. Process., vol. 27, pp. $1118-1122,2012$. [http://dx.doi.org/10.1080/10426914.2011.654162]

[43] J.Y. Zhang, S.Y. Liang, G. Zhang, and D. Yen, "Modelling of residual stress profile in finish hard turning", Mater. Manuf. Process., vol. 21, pp. 39-45, 2006. [http://dx.doi.org/10.1081/AMP-200060608]

[44] N.R. Dhar, M.W. Islam, S. Islam, and M.A.H. Mithu, "The influence of minimum quantity of lubrication (MQL) on cutting temperature, chip and dimensional accuracy in turning AISI-1040 steel", J. Mater. Process. Technol., vol. 171, no. 1, pp. 93-99, 2006. [http://dx.doi.org/10.1016/j.jmatprotec.2005.06.047]

[45] N.R. Dhar, S. Islam, and M. Kamruzzaman, "Effect of minimum quantity lubrication (MQL) on tool wear, surface roughness and dimensional deviation in turning AISI-4340 steel", Gazi University Journal of Science, vol. 20, no. 2, pp. 23-32, 2007.

[46] K.A. Risbood, U.S. Dixit, and A.D. Sahasrabudhe, "Prediction of surface roughness and dimensional deviation by measuring cutting forces and vibrations in turning process", J. Mater. Process. Technol., vol. 132, no. 1, pp. 203-214, 2003. [http://dx.doi.org/10.1016/S0924-0136(02)00920-2]

[47] N.R. Dhar, and M. Kamruzzaman, "Cutting temperature, tool wear, surface roughness and dimensional deviation in turning AISI-4037 steel under cryogenic condition", Int. J. Mach. Tools Manuf., vol. 47, no. 5, pp. 754-759, 2007.

[http://dx.doi.org/10.1016/j.ijmachtools.2006.09.018] 
[48] P.S. Paul, P. Raja, P. Aruldhas, S. Pringle, and E. Shaji, "Effectiveness of particle and mass impact damping on tool vibration during hard turning process", Proc. Inst. Mech. Eng., B J. Eng. Manuf., vol. 232, no. 5, pp. 776-786, 2018. [http://dx.doi.org/10.1177/0954405416660995]

[49] H.H. Shahabi, and M.M. Ratnam, "Prediction of surface roughness and dimensional deviation of workpiece in turning: A machine vision approach", Int. J. Adv. Manuf. Technol., vol. 48, no. 1-4, pp. 213-226, 2010. [http://dx.doi.org/10.1007/s00170-009-2260-z]

\section{(C) 2018 Yousefi and Zahoor.}

This is an open access article distributed under the terms of the Creative Commons Attribution 4.0 International Public License (CC-BY 4.0), a copy of which is available at: (https:/creativecommons.org/licenses/by/4.0/legalcode). This license permits unrestricted use, distribution, and reproduction in any medium, provided the original author and source are credited. 